\title{
МОРФО-БИОХИМИЧЕСКИЕ ПОКАЗАТЕЛИ КРОВИ КОРОВ ПРИ ВОССТАНОВЛЕНИИ ПОЛОВОЙ ЦИКЛИЧНОСТИ БИОГЕННЫМ ЛЕКАРСТВЕННЫМ ПРЕПАРАТОМ
}

\author{
N.V. Shanshin
}

\section{MORPHOLOGICAL AND BIOCHEMICAL PARAMETERS OF COWS' BLOOD IN THE COURSE OF RESTORATION OF ESTROUS CYCLE BY USING BIOGENIC MEDICINAL PRODUCT}

\author{
Шаньшин Николай Васильевич - канд. вете- \\ ринар. наук, вед. науч. сотр. лаб. разведения и \\ болезней животных Всероссийского НИИ панто- \\ вого оленеводства Федерального Алтайского \\ научного центра агробиотехнологий, г. Барнаул. \\ E-mail: wniipo@rambler.ru
}

Одним из препятствий интенсивного ведения молочного скотоводства является симптоматическое бесплодие коров, которое чаще всего обусловлено функциональными нарушениями яичников. Для улучшения воспроизводительной способности коров необходимо проводить мероприятия, направленные на улучшение обменных процессов в организме с использованием биологически активных средств, улучшающих общую резистентность животных в различные периоды репродуктивного цикла. К биологически активным средствам непосредственно относятся тканевые препараты, которые используются в качестве как вспомогательных, так и самостоятельных терапевтических средств, они усиливают обмен веществ, повышают энергетические процессы, жизненные функкци организма, увеличивают его сопротивляемость к болезнетворным факторам, улучшают регенеративные свойства, секреторную и моторную деятельность желудочно-кишечного тракта, сердечно-сосудистую деятельность, показатели крови. В связи с этим было изучено влияние нового биогенного лекарственного препарата на морфо-биохимические показатели крови коров, оценена эфффективность его применения в процессе восстановления половой иикличности животных. В ходе исследования было установлено, что подкожные инъекции биогенного лекарственного препарата в дозе 20 мл с интервалом в 14 дней способствуют повышению в крови коров общего количества гемоглобина на 9,6-29,7 \%, эритроцитов - соответственно на 30,8-39,2; лейкоци-
Shanshin Nikolay Vasilyevich - Cand. Veterinary Sci., Leading Staff Scientist, Lab. of Breeding and Animals Diseases, All-Russian Research Institute of Velvet Antler Reindeer Husbandry, Federal Altai Scientific Center of Agrobiotechnologies, Barnaul. E-mail: wniipo@rambler.ru

тов - на 11,3-36,7; альбуминов в сыворотке крови - на 31,3 \%; нормализации количества калия и магния в сыворотке крови, Са : Р соотношения 1,23-1,22-1,17: 1 в сравнении с исходными значениями. Половая цикличность восстановилась у 93,3 \% коров от общего числа участвующих в опыте, из них плодотворно осеменено 89,3 \%, соответственно в первый половой цикл 53,6 \%.

Ключевые слова: тканевые препараты, биогенный лекарственный препарат, эритроциты, гемоглобин, половая цикличность, плодотворное осеменение.

One of the challenges that intensive dairy farming faces is symptomatic infertility of cows, which is most often caused, by functional disorders of the animals' ovaries. In order to improve reproductive ability of cows, it is necessary to carry out activities aimed at the improvement of metabolic processes in the animal body using biologically active products enhancing the overall resistance of animals at various stages of reproductive cycle. Biologically active products include tissue preparations that are used as additional and independent therapeutic agents; such preparations enhance the animals' metabolism, facilitate energy processes and vital functions of the body, increase the resistance of the body to pathogenic factors, improve regenerative properties, as well as secretory and motor activity of gastrointestinal and intestinal tracts, cardiovascular activity, and blood indicators. In this regard the effect of a new biogenic medicinal product on morphological and biochemical parameters of cows' blood was studied, and the effectiveness of 
its use for the purpose of restoration of estrous cycle in animals was assessed. The research showed that subcutaneous injections with said biogenic product at a dose of $20 \mathrm{ml}$ at 14-day intervals increased the total hemoglobin in the blood of cows by $9.6-29.7 \%$ and the number of red blood cells by 30.8-39.2\%, respectively, whereas the number of white blood cells increased by 11.3-36.7 \%, and albumin in the blood serum increased by $31.3 \%$; the amount of potassium and magnesium in the blood serum normalized, the Ca : P ratio was 1.231.22-1.17: 1 as compared to the initial values. Regular estrous cycle was restored in $93.3 \%$ of the cows of the total number of the animals used in the experiment, $89.3 \%$ of which were successfully inseminated, and $53.6 \%$ were inseminated in their first estrus.

Keywords: tissue preparations, biogenic medicinal product, red blood cells, hemoglobin, estrous cycles, successful insemination.

Введение. Одним из препятствий интенсивного ведения молочного скотоводства является симптоматическое бесплодие коров, которое чаще всего обусловлено функциональными нарушениями яичников [1].

Неблагоприятные эндогенные и экзогенные фракторы, воздействующие на организм коров, способствуют развитию нарушений обменных процессов, что в дальнейшем приводит к снижению продуктивности, воспроизводительной функции и, как следствие, значительным экономическим потерям. Для улучшения продуктивности животных и воспроизводительной способности необходимо проводить мероприятия, направленные на улучшение обменных процессов в организме животных с использованием биологически активных средств, улучшающих общую резистентность животных в различные периоды репродуктивного цикла [2, 3].

К биологически активным средствам непосредственно относятся тканевые препараты, которые используются в качестве как вспомогательных, так и самостоятельных терапевтических средств, они усиливают обмен веществ, повышают энергетические процессы и жизненные функции организма, увеличивают его сопротивляемость к болезнетворным факторам, улучшают регенеративные свойства, секреторную и моторную деятельность желудочнокишечного тракта, сердечно-сосудистую деятельность, дыхание, показатели крови [4].
Цель исследования: изучить морфобиохимические показатели крови коров при восстановлении половой цикличности биогенным лекарственным препаратом.

\section{Задачи исследования:}

- изучить влияние биогенного лекарственного препарата на морфо-биохимический состав крови коров в процессе восстановления половой цикличности животных;

- оценить влияние биогенного лекарственного препарата на восстановление половой цикличности.

Материалы и методы исследования. Биогенный лекарственный препарат изготавливали в лаборатории разведения и болезней животных ФГБНУ ФАНЦА, отдел «ВНИИПО», по ранее запатентованной технологии (Патент РФ № 2682641); материалом служили побочная продукция и боенские отходы сельскохозяйственных животных. Опытную партию препарата проверяли на безвредность, токсичность - согласно ГОСТ 31926-2013 [5].

Научно-производственный опыт по испытанию биогенного лекарственного препарата проводили в хозяйствах Алтайского края, где были ссрормированы 2 группы яловых коров чернопестрой породы в возрасте 3-5 лактации, с диагнозом персистентное желтое тело и гипофункция яичников, с сервис-периодом свыше 90 дней в количестве 30 голов опытная группа (табл. 1) и 20 коров - контрольная (за которыми вели клиническое наблюдение и ничего не вводили). Опытным коровам испытуемый препарат вводили подкожно в область средней трети шеи, дробно в дозе 20 мл с интервалом 14 дней от 1 до 4 инъекций до проявления первой половой охоты. После выявления половых признаков охоты коров осеменяли и прекращали введение биогенного препарата как осемененным, так и неоплодотворенным животным. Эффективность изготовленного биогенного препарата оценивали по кратности введения, времени прихода в охоту, плодотворному осеменению.

Морфологические исследования крови - определение лейкоцитов, эритроцитов, содержание гемоглобина - по методу Г.А. Симоняна, Ф.Ф. Хисамутдинова (1995); содержание общего количества белка - рефрактометрически (ИРФ22), белковых фрракций - нефрелометрическим методом; минеральный состав в сыворотке крови определяли унифицированным методом с использованием наборов Vitaldiagnostic SPb на 
биохимическом фотометре «Стат Факс 1904 Плюс». Забор крови проводили перед первым введением препарата и через каждые 14 дней трижды. Оценку достоверности средних выборок оценивали по Стьюденту.

Результаты исследования. После инъекции биогенного лекарственного препарата (БЛП) коровам при восстановлении половой цикличности отмечали следующие морфо-биохимические изменения в составе крови (табл. 1). Общее количество гемоглобина в крови возросло на 29,7\% через 14 дней после первой инъекции, второй и третьей, соответственно - на 9,6 и $11,6 \%$; эритроцитов - на $39,2,30,8$ и $38,2 \%$ ( $p \leq 0,05)$, лейкоцитов - на 11,3; 32,4 и 36,7 \% соответственно. Общее количество белка в сы- воротке крови оставалось на всем протяжении опыта практически на одном уровне, а количество альбуминов достоверно увеличивалось после каждой инъекции, максимальное увеличение на $31,3 \%(p \leq 0,05)$ регистрировали во время завершающего забора крови, что указывает на более интенсивную активность белокобразующую функцию печени. Положительная динамика отмечена в улучшении Сa : Р соотношения 1,23-1,22-1,17: 1 после инъекций биогенного препарата в сравнении с исходным значением 0,96:1, нормализации количества калия и магния в сыворотке крови коров. В контрольной группе коров морфо-биохимические показатели крови в период наблюдения существенных различий с исходными данными не имели.

\section{Морфо-биохимические показатели сыворотки крови коров до и после введения биогенного лекарственного препарата}

Таблица 1

\begin{tabular}{|c|c|c|c|c|c|c|c|c|c|c|c|c|}
\hline \multirow{2}{*}{$\begin{array}{c}\text { Гемогло- } \\
\text { бин, г/л }\end{array}$} & \multirow{2}{*}{ 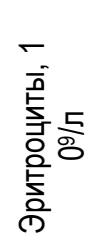 } & \multirow{2}{*}{ 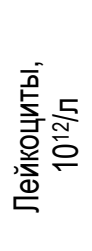 } & \multirow{2}{*}{ 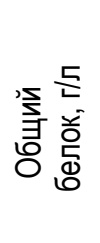 } & \multirow{2}{*}{ 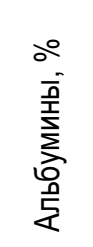 } & \multicolumn{3}{|c|}{ Глобулины, \% } & \multirow{2}{*}{ 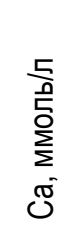 } & \multirow{2}{*}{$\begin{array}{l}\text { 들 } \\
\text { D } \\
\sum^{\circ} \\
\sum^{5} \\
\sum\end{array}$} & \multirow{2}{*}{ 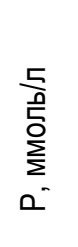 } & \multirow{2}{*}{$\begin{array}{l}\text { 돈 } \\
\text { 文 } \\
\text { ष् }\end{array}$} & \multirow{2}{*}{ 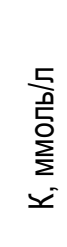 } \\
\hline & & & & & a & $\beta$ & Y & & & & & \\
\hline \multicolumn{13}{|c|}{ До введения БЛП (контрольная и опытная группы) } \\
\hline $\begin{array}{l}88,5 \pm \\
13,91\end{array}$ & $\begin{array}{l}5,0 \pm \\
0,35\end{array}$ & $\begin{array}{l}3,7 \pm \\
0,91\end{array}$ & $\begin{array}{c}73,5 \pm \\
3,33\end{array}$ & $\begin{array}{c}34,2 \pm \\
3,58\end{array}$ & $\begin{array}{c}15,8 \pm \\
3,50\end{array}$ & $\begin{array}{c}15,2 \pm \\
2,51\end{array}$ & $\begin{array}{c}34,7 \pm \\
6,31\end{array}$ & $\begin{array}{l}2,4 \pm \\
0,33\end{array}$ & $\begin{array}{l}1,8 \pm \\
0,19\end{array}$ & $\begin{array}{l}2,5 \pm \\
0,42\end{array}$ & $\begin{array}{l}124 \pm \\
15,0\end{array}$ & $\begin{array}{l}5,4 \pm \\
1,87\end{array}$ \\
\hline \multicolumn{13}{|c|}{ Опытная группа через 14 дней после первого введения БЛП } \\
\hline $\begin{array}{c}114,8 \pm \\
11,70\end{array}$ & $\begin{array}{l}6,7 \pm \\
0,64^{*}\end{array}$ & $\begin{array}{l}4,2 \pm \\
0,72\end{array}$ & $\begin{array}{c}73,3 \pm \\
2,02\end{array}$ & $\begin{array}{c}38,2 \pm \\
2,03\end{array}$ & $\begin{array}{c}10,7 \pm \\
4,10\end{array}$ & $\begin{array}{l}23,1 \pm \\
2,00^{*}\end{array}$ & $\begin{array}{c}28,3 \pm \\
4,21\end{array}$ & $\begin{array}{l}2,6 \pm \\
0,13\end{array}$ & $\begin{array}{c}1,0 \pm \\
0,21^{\text {** }}\end{array}$ & $\begin{array}{l}2,1 \pm \\
0,55\end{array}$ & $\begin{array}{c}142 \pm \\
11,5\end{array}$ & $\begin{array}{l}5,4 \pm \\
1,88\end{array}$ \\
\hline \multicolumn{13}{|c|}{ Опытная группа через 28 дней после первого введения БЛП } \\
\hline $\begin{array}{c}97,0 \pm \\
6,30\end{array}$ & $\begin{array}{l}6,6 \pm \\
0,72^{*}\end{array}$ & $\begin{array}{l}4,9 \pm \\
1,03\end{array}$ & $\begin{array}{c}75,3 \pm \\
2,06\end{array}$ & $\begin{array}{c}36,5 \pm \\
3,07\end{array}$ & $\begin{array}{c}10,7 \pm \\
4,13\end{array}$ & $\begin{array}{c}11,0 \pm \\
1,20\end{array}$ & $\begin{array}{c}37,9 \pm \\
2,46\end{array}$ & $\begin{array}{l}2,7 \pm \\
0,26\end{array}$ & $\begin{array}{l}1,1 \pm \\
0,19^{\star}\end{array}$ & $\begin{array}{l}2,2 \pm \\
0,28\end{array}$ & $\begin{array}{l}106 \pm \\
51,0\end{array}$ & $\begin{array}{l}4,0 \pm \\
2,43\end{array}$ \\
\hline \multicolumn{13}{|c|}{ Опытная группа через 32 дней после первого введения БлП } \\
\hline $\begin{array}{l}98,8 \pm \\
15,91\end{array}$ & $\begin{array}{l}6,9 \pm \\
0,68^{*}\end{array}$ & $\begin{array}{l}5,1 \pm \\
1,02\end{array}$ & $\begin{array}{c}73,5 \pm \\
3,53\end{array}$ & $\begin{array}{l}44,9 \pm \\
2,75^{*}\end{array}$ & $\begin{array}{c}11,6 \pm \\
3,31\end{array}$ & $\begin{array}{c}21,5 \pm \\
2,08\end{array}$ & $\begin{array}{l}20,1 \pm \\
2,12^{*}\end{array}$ & $\begin{array}{l}2,7 \pm \\
0,25\end{array}$ & $\begin{array}{l}1,3 \pm \\
0,21\end{array}$ & $\begin{array}{l}2,3 \pm \\
0,23\end{array}$ & $\begin{array}{l}107 \pm \\
42,0\end{array}$ & $\begin{array}{l}3,6 \pm \\
0,78\end{array}$ \\
\hline
\end{tabular}

${ }^{*} p \leq 0,05 ;{ }^{* *} p \leq 0,01$.

Восстановление половой цикличности после применения биогенного лекарственного препарата с интервалом в 14 дней представлена в таблице 2. Положительные результаты по восстановлению половой охоты отмечены у $20,0 \%$ подопытных коров в течение 7-12 сут после первой инъекции, соответственно у 10,0 \% после второй, 16,6 и 46,6 \% - после третьей и четвертой инъекции биогенного лекарственного препарата. 
Эффективность применения биогенного лекарственного препарата при восстановлении половой цикличности коров

\begin{tabular}{|c|c|c|c|c|c|}
\hline \multirow[b]{2}{*}{ Показатель } & \multicolumn{4}{|c|}{ Кол-во коров, отреагировавших на инъекцию препарата, гол. } & \multirow[b]{2}{*}{$\begin{array}{c}\text { Итого } \\
\text { (за период } \\
\text { исследований) }\end{array}$} \\
\hline & $\begin{array}{c}\text { После } \\
\text { первой } \\
\text { инъекции }\end{array}$ & $\begin{array}{c}\text { Второй } \\
\text { инъекции }\end{array}$ & $\begin{array}{c}\text { Третьей } \\
\text { инъекции }\end{array}$ & $\begin{array}{l}\text { Четвертой } \\
\text { инъекции }\end{array}$ & \\
\hline Пришло в охоту, гол. (\%) & $6(20,0)$ & $3(10,0)$ & $5(16,6)$ & $14(46,7)$ & $28(93,3)$ \\
\hline $\begin{array}{l}\text { Плодотворно осеменено } \\
\text { в } 1 \text { охоту, гол. }\end{array}$ & 3 & 1 & 3 & 8 & $15(53,6)$ \\
\hline $\begin{array}{l}\text { Плодотворно осеменено } \\
\text { за весь период наблю- } \\
\text { дения, гол. }\end{array}$ & 6 & 3 & 5 & 11 & $25(89,3)$ \\
\hline
\end{tabular}

После окончания курса терапии испытуемым препаратом половая цикличность восстановилась у 28 подопытных коров, что составляет 93,3 \% от общего числа участвующих в опыте, из них плодотворно осеменено 89,3\%, соответственно в первый половой цикл - 53,6 \%. В контрольной группе животных за 60-дневный период наблюдений половая цикличность восстановилась у 6 коров $(30,0 \%)$, из них плодотворные осеменения в первую половую охоту отсутствовали. Исследования по использованию БЛП для восстановления половой цикличности у коров в послеродовый период продолжаются, необходимо более детальное изучение кратности, дозы введения и широкое производственное испытание препарата.

Выводы. Биогенный лекарственный препарат, вводимый подкожно в дозе 20 мл/гол с интервалом в 14 дней, оказывает нормализующее физиологическое воздействие на гематологические, биохимические и репродуктивные показатели коров. Инъекции биогенного лекарственного препарата способствуют повышению общего количества гемоглобина в крови на 9,6-29,7 \%; эритроцитов соответственно - на 30,8-39,2; лейкоцитов - на 11,3-36,7; альбуминов в сыворотке крови - на $31,3 \%$. Положительная динамика отмечена в улучшении Са : Р соотношения 1,23-1,22-1,17 : 1 после инъекций биогенного препарата в сравнении с исходным значением $0,96: 1$, нормализации количества калия и магния в сыворотке крови коров. Половая цикличность восстановилась у 93,3 \% коров от общего числа участвующих в опыте, из них плодотворно осеменено 89,3\%, соответственно в первый половой цикл - 53,6 \%.

\section{Литература}

1. Зверева Г.В., Хомин С.П. Гинекологические болезни коров. Киев: Урожай, 1976. 152 с.

2. Землянкин B.B. Коррекция репродуктивной функции у коров с фолликулярными кистами яичников: дис. ... канд. ветеринар. наук. Саратов, 2004. 170 c.

3. Хабиб Д.Х. Показатели крови и репродуктивной функции коров при применении фитопрепаратов: дис. ... канд. ветеринар. наук. Саранск, 2017. 177 с.

4. Даричева Н.Н., Ермолаев В.А. Тканевая терапия в ветеринарной медицине. Ульяновск: УГСХА, 2011. 168 с.

5. ГОСТ 31926-2013. Средства лекарственные для ветеринарного применения. Методы определения безвредности. М.: Стандартинсрорм, 2014.

\section{Literatura}

1. Zvereva G,V., Homin S.P. Ginekologicheskie bolezni korov. - Kiev: Urozhaj, 1976. - 152 s.

2. Zemljankin V.V. Korrekcija reproduktivnoj funkcii $u$ korov $s$ follikuljarnymi kistami jaichnikov: dis. ... kand. veterinar. nauk. Saratov, 2004. $170 \mathrm{~s}$.

3. Habib D.H. Pokazateli krovi i reproduktivnoj funkcii korov pri primenenii fitopreparatov: dis. ... kand. veterinar. nauk. Saransk, 2017. $177 \mathrm{~s}$.

4. Daricheva N.N., Ermolaev V.A. Tkanevaja terapija $v$ veterinarnoj medicine. Ul'janovsk: UGSHA, 2011. $168 \mathrm{~s}$.

5. GOST 31926-2013. Sredstva lekarstvennye dlja veterinarnogo primenenija. Metody opredelenija bezvrednosti. M.: Standartinform, 2014. 